\title{
ANÁLISE DO ÍNDICE DE ÁREAS VERDES (IAV) NA ÁREA CENTRAL DA CIDADE DE JUIZ DE FORA, MG
}

\author{
COSTA, Renata Geryani S. ${ }^{1}$; FERREIRA, Cácia Castro M. ${ }^{2}$ \\ (recebido em 27.10.2008 e aceito para publicação em 26.03.2009)
}

\begin{abstract}
RESUMO
A vegetação é capaz de promover significativas melhorias no ambiente urbano, principalmente no que se refere à redução da poluição atmosférica, à minimização das temperaturas, ao conforto ambiental, além de causar bem-estar físico e psíquico, atuando, conseqüentemente, na qualidade de vida. O presente trabalho procurou conhecer a oferta de áreas verdes a partir do cálculo do Índice de Áreas Verdes (IAV) em 24 Regiões Urbanas de Juiz de Fora. Constatou-se reduzida presença de áreas verdes, sendo que apenas uma única região urbana apresentou um IAV acima do sugerido na Carta a Londrina e Ibiporã, que é de $15 \mathrm{~m}^{2} /$ habitantes. Todas as demais áreas estiveram muito abaixo deste mínimo. Neste sentido, este trabalho vem confirmar o déficit de áreas verdes, que, atrelado a dinâmica urbana, prejudica a qualidade de vida da população.
\end{abstract}

PALAVRAS-CHAVE: áreas verdes, conforto ambiental, desenvolvimento urbano, índice de áreas verdes.

1. Graduada em Licenciatura pelo curso de Geografia, bolsista de Iniciação Científica PROBIC/FAPEMIG. Universidade Federal de Juiz de Fora, Instituto de ciências Humanas, Departamento de Geociências, Juiz de Fora - MG. Tel: (32) 3229-3108. E-mail: <renatageniany@yahoo.com.br>

2. Prof ${ }^{\mathrm{a}} \mathrm{Dr}^{\mathrm{a}}$ do Departamento de Geociências. Universidade Federal de Juiz de Fora, Juiz de Fora MG. Tel: (32) 3229-3108. E-mail: <cássia.castro@ufjf.edu.br> 


\title{
ANALYSIS THE INDEX OF GREEN AREAS IN THE CENTRAL AREA IN JUIZ DE FORA CITY, MG
}

\begin{abstract}
The vegetation can promove adcvances in the urban ambient, mainly in as refer to the reduction of the atmosphere pollution the minimization of the temperatures, the ambiental comfort and cause welfare physical and psychic helping in a best quality of life. The present work find know the green areas since the calculation of index of green areas in 24 urban regions in Juiz de For a. Certifyed reduced presence of green areas, and just one urban region showing an IAV up in the letter to Londrina e Ibiporâ as is $15 \mathrm{~m}^{2} /$ person. All the others areas been very down this minimum. This work, come confirm de deficit of the green areas as together the urban dynamics prejudice the quality of life the population.
\end{abstract}

KEYWORDS: green areas, ambiental comfort, urban grown, index of green áreas. 
Análise do índice de áreas verdes...

\section{INTRODUÇÃO}

A retirada progressiva da vegetação, em consequência do crescimento das cidades provoca alterações no ambiente natural e, ou, construído como mudanças nos microclimas, topoclimas e mesoclimas. Constitui-se, desta maneira, um clima urbano (MONTEIRO, 2003), que se diferencia do entorno rural, em termos de temperatura, qualidade do ar, radiação solar e regimes de precipitação.

Em função das atividades fisiológicas desempenhadas pela vegetação, ela é capaz de promover significativas melhorias no ambiente urbano, principalmente no que se refere à redução da poluição atmosférica, à minimização das temperaturas, ao conforto lúmnico e acústico, além de promover bem-estar físico e psíquico ao ser humano, atuando, consequentemente, na sua qualidade de vida.

As áreas verdes, por serem espaços livres cujo elemento fundamental de composição é a vegetação, sua presença pode auxiliar na indicação de áreas com melhor qualidade de vida nos ecossistemas urbanos.

Entretanto, ainda é grande a discussão na busca de uma padronização de conceito e utilização de uma metodologia que, permita a comparação entre as pesquisas já desenvolvidas acerca do verde urbano. Verifica-se que conceitos como áreas verdes, espaços livres, cobertura vegetal, entre outros, são empregados indistintamente como sinônimos, como se desempenhassem uma mesma função (CAVALHEIRO e DEL PICCHIA, 1992). Logo, sem ter a pretensão de esgotar a discussão sobre o tema, procurou-se tecer alguns esclarecimentos acerca das terminologias empregadas em diferentes trabalhos.

Lima et al. (1994), detectaram a dificuldade no consenso das terminologias do verde urbano entre profissionais que trabalham ou pesquisam esta temática na região sudeste brasileira, e mostram que essa discussão existe em todo o decorrer da história, já que,

"originalmente, os espaços das cidades medievais e
renascentistas, não eram arborizados e passaram a sê-lo, a partir
do século XIX, quando as autoridades começaram a ter
preocupações, tanto de ordem estética como sanitárias,
resolvendo por oferecer "pulmões verdes" (sic) às cidades."
(RICHTER, 1981; TANDY, 1982 apud LIMA et al., 1994)

Lima et al. (op cit.), ainda, fizeram uma proposta de conceituação de alguns termos, e opinaram que o termo espaço livre seria o mais abrangente, integrando os demais e contrapondo-se ao espaço construído. 
Merece destacar na conceituação proposta por esses autores, a inclusão de espaços como canteiros e trevos de vias públicas, que tem apenas funções estética e ecológica, também conceituarem-se como área verde. Inclusão esta, que não é compartilhada por outros autores tais como Nucci (1996) e Cavalheiro et al. (1999).

Nucci (1996) mostra que os canteiros que cumprem apenas função estética e ecológica, não podem ser considerados área verde, uma vez que, não cumprem função de lazer. Cavalheiro et al. (1999), considera que além dos canteiros, as rotatórias, pequenos jardins de ornamentação e arborização, não podem ser considerados áreas verdes, mas sim verde de acompanhamento viário, que junto às calçadas constituem categoria de espaços construídos ou de integração urbana.

Paiva e Gonçalves (2002) descrevem que seria possível ter áreas verdes compostas por apenas uma ou duas árvores, todavia, com importância evidente do ponto de vista científico, por exemplo. Introduzem, ainda, o termo "floresta urbana" para designar áreas verdes produtivas (cuja finalidade é a produção de bens de consumo oriundos das árvores) e áreas verdes de preservação ou conservação (cuja finalidade é a conservação do sítio ou a manutenção da biodiversidade), colaborando com outro posicionamento relevante, ao inserir as unidades de conservação no sistema áreas verdes utilizando outra terminologia, na tentativa de diferenciá-las das demais categorias.

Pela abrangência do termo, Cavalheiro e Del Picchia (op cit.) e Guzzo e Cavalheiro (2000) preferem o uso espaço livre ao de áreas verdes e destacam que os espaços livres devem desempenhar função estética, ecológica e de lazer. Como função estética, pode-se considerar o que se refere ao belo, formoso e agradável; já a função ecológica diz respeito, dentre outras, à capacidade de redução dos materiais tóxicos particulados e sua incorporação nos ciclos biogeoquímicos, à manutenção do micro-clima, da fauna e das altas taxas de evapotranspiração, enquanto que a função de lazer refere-se ao descanso, ócio ou passatempo. Estas funções já foram descritas e reafirmadas por outros autores (LIMA et al., 1994; CAVALHEIRO et al., 1999; NUCCI, 1996; HENKE-OLIVEIRA, 1996; GUZZO e CAVALHEIRO, 2000; BUCCHERI-FILHO e NUCCI, 2006).

Guzzo e Cavalheiro (2000) fizeram referência à função social desempenhada pelos espaços livres, ao afirmarem que "os espaços livres de uso público têm uma importância relevante, pois são eles onde há possibilidade de convívio social e cujo acesso à população é sempre livre". Entretanto, estes mesmos autores, destacaram que nem todo espaço livre é composto por vegetação, pois existem praças públicas inteiramente impermeabilizadas e com pouca ou nenhuma composição de plantas.

Além das funções já descritas, Henke-Oliveira (1996) destacou também a função econômica dos espaços livres de uso público. A função econômica pode estar associada aos benefícios da arborização urbana, como a geração de empregos diretos ou indiretos 


\section{Análise do índice de áreas verdes...}

(DETZEL, 1992 apud HENKE-OLIVEIRA, 1996) ou ao montante de recursos financeiros despendidos nos tratamentos hospitalares; ou ainda estaria associada à valoração das propriedades (MILANO 1992 apud HENKE-OLIVEIRA, 1996). Imóveis próximos às áreas verdes têm um valor agregado 5-15\% superior que em áreas desprovidas de arborização (KIELBASO, 1994 apud HENKE-OLIVEIRA, 1996).

Na definição adotada por Henke-Oliveira (op cit.), destaca-se que as áreas verdes devem apresentar predomínio de vegetação, preferindo-se a arborização, ou seja, elementos vegetais de porte arbóreo. Cavalheiro et al. (1999), vai de encontro à esse posicionamento ao relatar que, as áreas verdes seriam um tipo especial de espaços livres onde o elemento fundamental de composição é a vegetação.

Com base na proposta de Cavalheiro et al. (1999), os autores Buccheri-Filho (2006), Buccheri-Filho e Nucci (2006), elaboraram um fluxograma, no qual um espaço livre, para ser classificado como área verde, deve apresentar respostas positivas às seguinte perguntas: 1 ) a vegetação é o elemento fundamental de composição? 2) cumpre funções: ecológica, estética e de lazer? 3) área com $70 \%$ de cobertura vegetal em solo permeável (sem laje)? 4) serve à população? 5) propicia condições para recreação?

Cavalheiro e Del Picchia (1992), Henke-Oliveira (1996), Cavalheiro et al. (1999), concordam que toda área verde é um espaço livre, porém nem todo espaço livre pode ser considerado área verde.

Frente à essa afirmativa, entende-se que são inegáveis os benefícios de um planejamento da área urbana que priorizem a presença e a distribuição mais equitativa dos espaços livres. Entretanto, vale considerar que, preferir o emprego desse termo ao de áreas verdes pode acabar por desvalorizar a vegetação e os benefícios que estas áreas podem oferecer para um ambiente mais saudável na cidade. Segundo Nucci (1996), o espaço livre, para exercer as funções estética, ecológica e de lazer, não deveria estar totalmente desvinculado da vegetação. Logo, se é possível existirem espaços livres sem vegetação (GUZZO e CAVALHEIRO, 2000), a área verde, como uma categoria de espaço livre público, torna-se proeminente, por ser a vegetação o principal elemento de diferenciação de sua terminologia.

A cobertura vegetal é, muitas vezes, confundida com áreas verdes, mascarando e dificultando a comparação de índices numa mesma cidade. Comumente, são confundidos o Índice de Área Verde utilizado em diversos trabalhos (HENKE-OLIVEIRA, 1996; HARDER, 2002; BUCCHERI-FILHO, 2006) e Índice de Verde (NUCCI 1996), também chamado Índice de Cobertura Vegetal (ROSSET, 2005), por serem ambos dependentes da demografia, ou seja, são calculados em função da população, expressando a oferta de serviços per capita. 
Outros termos, como Verde Urbano (GUZZO e CAVALHEIRO, 2000) e Manchas Verdes (NUCCl, 1996), utilizados em alguns trabalhos, são, na verdade, sinônimos de cobertura vegetal.

A cobertura vegetal seria, segundo Cavalheiro et al. (1999), toda vegetação existente nos três sistemas: espaços livres de construção, espaços de integração urbana e espaços com construções, e as encontradas nas Unidades de Conservação e na zona rural (MOURA e NUCCI, 2005).

Segundo Moura e Nucci (2005) essa conceituação sugerida por Cavalheiro et al. (1999), vem se mostrando de fácil entendimento e de grande utilidade para o planejamento e avaliação da qualidade dos espaços urbanos.

Nucci (1996), referindo-se à cobertura vegetal como "manchas verdes", opinou que estas não poderiam ser consideradas áreas verdes, pois nem todas podem ser utilizadas para o uso do lazer. Portanto, entende-se que a área verde esta abrangida pela cobertura vegetal.

A cobertura vegetal englobaria, assim, toda vegetação, seja de porte arbóreo, hebáceo ou arbustivo, independente da tipologia ou categoria que ocupa. Já a Arborização Urbana diz respeito apenas aos elementos vegetais de porte arbóreo dentro da área urbana (LIMA et al., 1994).

Lima et al. (1994), Henke-Oliveira (1996), Cavalheiro et al. (1999) e Guzzo e Cavalheiro (2000), concordaram que a arborização em calçadas ou arborização de acompanhamento viário ou verde viário não pode ser considerada como área verde, sendo uma categoria distinta das demais tratadas até aqui.

Apesar dos diferentes conceitos e abordagens apresentados, muitos deles enfocam um ponto ou outro que destacam como mais relevante para definir a terminologia dos espaços discutidos e, por isto, apresentam semelhanças fundamentais que poderíamos interpretar como palavras-chaves na diferenciação desses espaços, tais como presença ou ausência de vegetação, função desenvolvida, porte e localização da vegetação.

É importante enfatizar que cada um desses conceitos foi construído dentro de um processo da realidade vivenciada por cada autor, em sua cidade ou em outras cidades, que porventura sejam conhecidas por estes. Logo, conhecendo as disparidades históricas de construção do espaço urbano no Brasil, estes conceitos não podem ser considerados como conflitantes entre si, mas sim, complementares.

Apesar da necessidade de estudos que enfoquem a discussão dos conceitos que definem a vegetação dentro do espaço urbano, estudos que buscam conhecer a presença ou ausência desses espaços ligados a qualidade ambiental e de vida, também merecem atenção. 
Análise do índice de áreas verdes...

Pensando nisso, o presente trabalho teve como escopo conhecer a oferta de áreas verdes para população situada em 24 Regiões Urbanas na área central da cidade de Juiz de Fora, MG, a partir do cálculo do Índice de Áreas Verdes (IAV); uma vez que têm sido verificadas na área urbana da cidade de Juiz de Fora, nos últimos anos, um aumento da emissão de poluentes para a atmosfera (MARTINS E TORRES, 2001; REZENDE, 2005), alterações no regime de chuvas e aumento da temperatura (STAICO, 1976; MARTINS, 1996, SANTOS et al., 2005). Conhecendo os benefícios trazidos pelas áreas verdes na minimização dos impactos negativos dessas alterações, entende-se que seja necessário o desenvolvimento de estudos como este, que visem a avaliar e quantificar as áreas verdes presentes, em especial, na cidade de Juiz de Fora, que concentra cerca de 99,17\% (ANUÁRIO ESTATíSTICO, 2005) da população de 513 mil habitantes (IBGE, 2007) em sua área urbana.

\section{MATERIAIS E MÉTODOS}

Juiz de Fora é uma cidade de porte médio localizada a sudeste do Estado de Minas Gerais, na Mesorregião geográfica da Zona da Mata. De acordo com a Lei Municipal № 6910/86, o município de Juiz de Fora tem sua superfície divida em Área Urbana e Área Rural. A Área Urbana, por sua vez, é subdividida, por esta mesma lei, em Zona Urbana (espaços da área urbana que englobam, predominantemente, as áreas caracterizadas como urbanizadas e ocupadas, podendo compreender pequenos vazios, que são áreas não ocupadas existentes no interior da malha urbana) e Zona de Expansão Urbana (espaço da área urbana que compreende, predominantemente, espaços vazios e pouco adensados, previstos para expansão urbana da cidade). Porém esta divisão da área urbana agrupa uma área muito grande e heterogênea.

Assim, na busca de uma compartimentação urbana mais adequada e detalhada que pudesse ser utilizada no planejamento, foram estabelecidas, em 1986, pela Lei № 7619/89, 81 Regiões Urbanas (RU's), que subdividem a porção mais contínua e densamente ocupada do município - a zona urbana.

Segundo o Plano Diretor de Desenvolvimento Urbano de Juiz de Fora (IPLLAN1996), essas regiões acabaram se tornando as principais células dos estudos urbanos na cidade, por se revelarem mais homogêneas. Em função dos limites devidamente estabelecidos, o senso demográfico de 2000 (IBGE, 2000) fixou os setores censitários com base nas Regiões Urbanas.

Como o Índice de Áreas Verdes (IAV) é um indicador dependente da população, as regiões urbanas foram adotadas como a unidade espacial para este trabalho. Foram selecionadas 24 Regiões Urbanas, na área central da cidade, para compor a unidade de 
estudo (Figura 1), são elas: Fábrica, Mariano Procópio, Morro da Glória, Santa Catarina, Vale do Ipê, Jardim Glória, Jardim Santa Helena, Jardim Paineiras, São Mateus, Santa Cecília, Mundo Novo, Alto dos Passos, Boa Vista, Bom Pastor, Vila Ozanan, Poço Rico, Grambery, Centro, Botanágua, Manoel Honório, Bairu, Centenário, Santa Terezinha, Eldorado. Tais regiões não individualizam bairros, recebendo apenas o nome do bairro principal que abrange. No entanto, as RUs tratadas no presente trabalho correspondem cada uma, ao bairro de mesmo nome.

Essas RU's podem ser divididas em grupos, que possibilitem uma descrição de suas características predominantes. O primeiro grupo é composto por Santa Helena, Paineiras, Centro, São Mateus, Alto dos passos, Bom Pastor e Granbery, que se caracterizam por uma ocupação de padrão sócio-econômico médio a alto. Sofrem grande pressão imobiliária voltada para verticalização, que vem provocando uma renovação urbana, e são totalmente dependentes da área central, com exceção de São Mateus.

O segundo grupo é composto por Santa Cecília, Mundo Novo, Eldorado e Vila Ozanan. Apresentam um padrão de ocupação bem inferior, apresentam padrão predominantemente familiar, e nível sócio-econômico baixo a médio. O sistema viário é composto por vias estreitas de declividades acentuadas. Há ocorrência de ocupações em área de risco (encostas declivosas).

Um terceiro grupo relaciona Poço Rico, Botanágua, Fábrica, Mariano Procópio, Manoel Honório, Santa Terezinha e Centenário, que cumprem função de corredor de comercio e de tráfego urbano e regional. Apresenta padrões sócio-econômicos médios e conta com a presença de uso comercial e industrial, a exceção do Centenário.

Bairu, Morro da Glória, Santa Catarina e Jardim Glória compõem o quarto grupo. Possuem predominância residencial, a exceção do Morro da Glória que apresenta uma tendência a verticalização. O padrão sócio-econômico é de médio a alto, com predominância unifamiliar.

Por fim, temos Boa Vista e Vale do Ipê, que se destacam por excelentes padrões de residências, unifamiliares, e nível sócio-econômico alto. (IPPLAN, 2000).

A área central foi escolhida por se situar onde, historicamente, ocorreram as primeiras ocupações da cidade, constituindo a parte mais densamente ocupada, onde se observa um acelerado processo de verticalização nos últimos anos.

A paisagem atual dessa área, assim como toda cidade, foi configurada pela especulação imobiliária, pela favelização e pela ocupação e degradação de áreas naturais. Muitos dos espaços verdes que existiam, obedecendo à dinâmica do processo de urbanização, foram sendo fracionados e incorporados à malha urbana. A vegetação mais proeminente existente hoje está concentrada em unidades de conservação (APAs, Reservas Biológicas, e Parques), protegidas pela legislação municipal, localizadas na periferia da 
Análise do índice de áreas verdes...

cidade ou em locais de difícil acesso. Todo este processo acaba por influenciar negativamente a qualidade de vida da população.

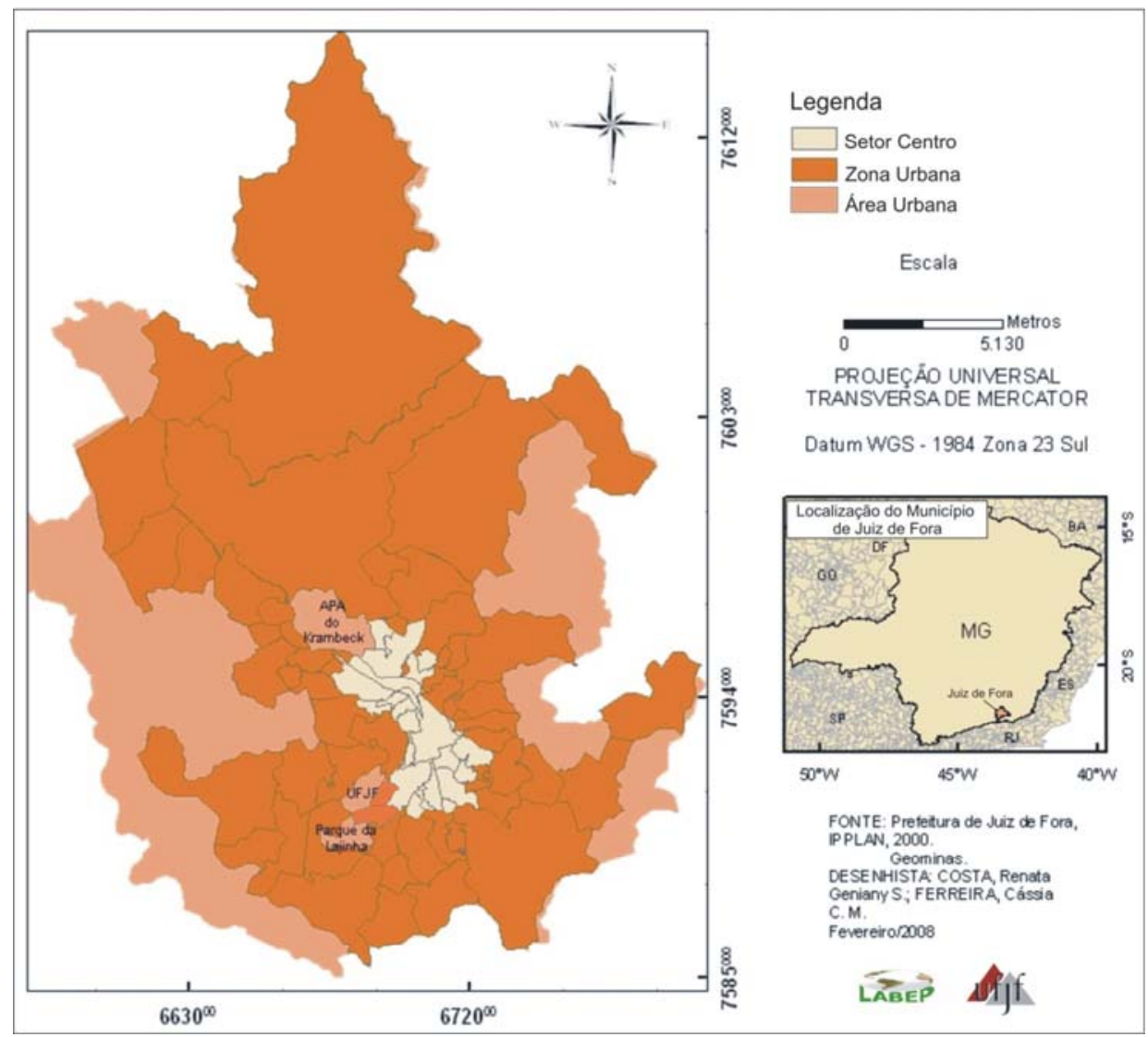

Figura 1: Localização da unidade de estudo

Segundo Henke-Oliveira (1996), o IAV expresso em metros quadrados $\left(\mathrm{m}^{2}\right)$ de área verde por habitante é abordado como um indicador da qualidade de vida, expressando a oferta de área verde per capita.

Índices são números que procuram descrever um determinado aspecto da realidade, ou apresentam uma relação entre vários aspectos (ROSSET, 2005). E segundo HenkeOliveira (op cit), mesmo representando um conceito complexo como a qualidade de vida, os índices podem sintetizar um conjunto de aspectos da realidade, desde que sejam adotadas técnicas para determinação dos valores.

Frente à complexidade do conceito de qualidade de vida tratada por outros trabalhos (MAZETTO, 2000), a "qualidade de vida" foi considerada neste trabalho, segundo TROPPMAIR (1992) apud MAZETTO (2000), como "os parâmetros físicos, químicos, biológicos, psíquicos e sociais que permitam o desenvolvimento harmonioso, pleno e digno da vida". 
Apesar de ser utilizado por diversos autores (HENKE-OLIVEIRA, 1996; ROSSET, 2005; BUCCHERI-FILHO, 2006; COSTA e FERREIRA, 2007), o estabelecimento de um IAV mínimo é ainda um assunto bastante discutido. Porém, como não se pretende, no presente trabalho, aprofundar esta discussão já abordada por outros trabalhos (CAVALHEIRO e DEL PICCHIA, 1992), optou-se por adotar, como base para comparação, o índice áreas verdes públicas destinadas para recreação, sugerido na Carta a Londrina e Ibiporã, (SBAU, 1996), que é de $15 \mathrm{~m}^{2}$ por habitante, como sendo o mínimo de áreas verdes para assegurar a qualidade de vida.

Embora apresente diferentes entendimentos, neste trabalho, as áreas verdes tratadas podem ser descritas segundo, COSTA e FERREIRA (2007), como áreas públicas, pois tal categoria apresenta diferenças quanto aos benefícios à população. Alguns benefícios (controle micro-climático, poluição, saúde física e mental, etc.) são propiciados pelas áreas verdes em geral; contudo, no que diz respeito às áreas verdes públicas, estas têm efeito direto em questões como recreação ao ar livre e valorização econômica dos espaços (MILANO, 1990).

Cavalheiro et al (1999) sugeriram um conceito de áreas verdes, porém, em um estudo recente, COSTA e FERREIRA (2008) constataram que este conceito se mostrou bastante restritivo ao ser aplicado à realidade da cidade de Juiz de Fora, pois o que determinou que algumas praças não fossem classificadas como áreas verdes foi o fato de estas apresentarem permeabilidade abaixo de $70 \%$, já que satisfaziam a outros requisitos como lazer, recreação e predominância de cobertura vegetal arbórea. Este fato está pautado no projeto especial de urbanização de praças definido pelo Decreto № 4128 - de 30 de março de 1989, no qual o órgão responsável pela manutenção das praças, a Empresa Municipal de Pavimentação e Urbanização - EMPAV, promove a impermeabilização de quase toda a superfície dessas áreas, em prol da urbanização.

Para a delimitação do tamanho, da forma e da distribuição das áreas verdes na unidade de estudo, foi utilizado o SIG - Sistema de Informação Geográfica - Arc View GIS. Essa tecnologia permite capturar, armazenar, checar, manipular, analisar e exibir dados, os quais são espacialmente referenciados a terra. (DOE, 1987 apud SILVA, 1999).

Com base em fotos aéreas datadas do ano de 2000, foram delimitados todos os espaços reconhecidos como áreas verdes na escala de 1:2000 no Laboratório de Estudos da Paisagem (LABEP), situado no Departamento de Geociências da Universidade Federal de Juiz de Fora.

Após a delimitação das áreas verdes e visitas ao campo para verificação dos dados obtidos em laboratório, foram calculados os valores de áreas verdes em metros quadrados $\left(\mathrm{m}^{2}\right)$ para cada região urbana que apresentou, ao menos, uma área verde. 
Análise do índice de áreas verdes...

O IAV foi estabelecido a partir do somatório das áreas verdes em $\mathrm{m}^{2}$ dividido pela população da respectiva Região Urbana. Este método de cálculo do IAV é utilizado por diversos trabalhos, podendo-se destacar os de MILANO (1990); HENKE-OLIVEIRA et al. (1994); HARDER (2002); COSTA e FERREIRA (2007).

A utilização do SIG permitiu, ainda, uma visão da distribuição espacial das áreas verdes com base no IAV obtido para cada Região Urbana, a partir da geração de um produto cartográfico na escala de 1:45000 da área central, possibilitando tecer análises a respeito de sua ocorrência e distribuição.

\section{RESULTADOS E DISCUSSÃO}

O IAV encontrado para cada uma das 24 Regiões Urbanas de Juiz de Fora reflete bem o seu processo de crescimento sem um planejamento que priorizasse a manutenção e multiplicação de áreas verdes públicas.

Deve-se ter cuidado ao fazer comparações entre os diferentes IAV encontrados em outros trabalhos, uma vez que, a comparação entre IAV pode ser um equívoco, pois a falta de definição clara do termo "área verde" e seus correlatos, as diferentes escalas adotadas e metodologias de coleta de dados diferenciadas, podem levar a falsas interpretações e a um uso político não muito correto (NUCCl, 2001).

Apesar das diferenças presentes entre os trabalhos que buscam calcular o IAV, um fato é claro em todos estes: há um déficit de áreas verdes na maioria das cidades brasileiras, acompanhado de um crescimento sem planejamento, que pode, também, ser constatado nos diferentes bairros que compõe a unidade de estudo.

Como pode ser visualizado no Mapa de Distribuição do IAV (Figura 2), das 24 Regiões Urbanas analisadas, 23 apresentaram um IAV abaixo de 2,5 $\mathrm{m}^{2} / \mathrm{hab}$. Logo, a baixa presença de áreas verdes, associada ao acelerado processo de urbanização, acaba influenciando diretamente nas condições do ambiente e consequentemente na qualidade de vida desta população. 


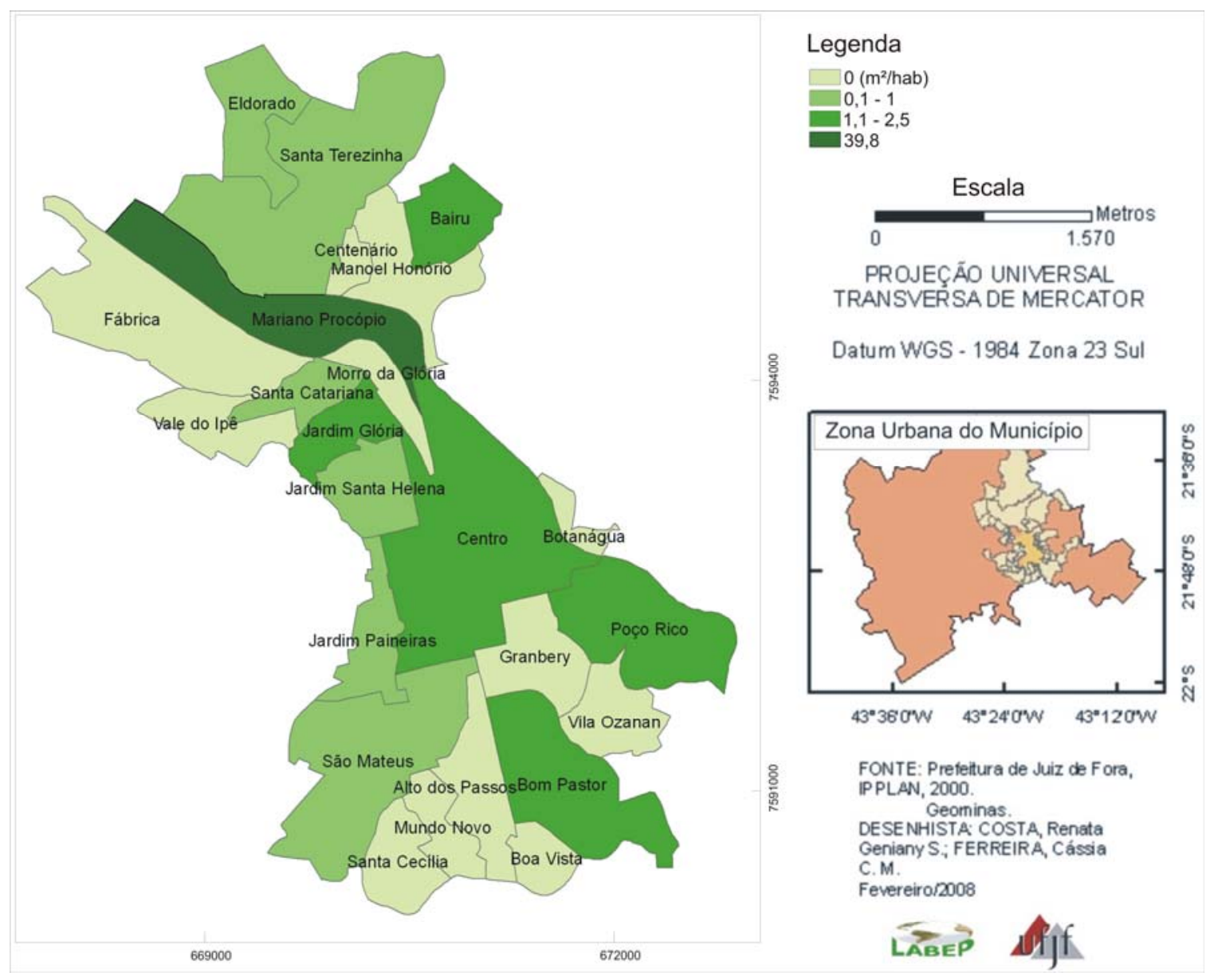

Figura 2: Mapa de Distribuição do Índice de Áreas Verdes (IAV) na área central da cidade de Juiz de Fora, MG

Entre as 24 Regiões Urbanas pesquisadas, 12 apresentaram um IAV igual a 0 (zero) $\mathrm{m}^{2} /$ hab (Tabela 1), valor preocupante frente à configuração do sítio urbano, principalmente se comparado ao uso do solo neste setor.

Pode-se considerar que as Regiões Urbanas, Santa Helena, Paineiras, Centro, São Mateus, Alto dos passos, Bom Pastor, Granbery, Poço Rico, Santa Terezinha, Botanágua, Fábrica e Centenário apresentaram a pior situação para população frente ao baixo IAV constatado, já que, concentram função de corredor de comércio e de tráfego urbano, grande pressão voltada à verticalização, e uso do solo comercial, residencial e industrial.

As RU's Poço Rico, Santa Terezinha e Mariano Procópio, apesar de apresentarem baixos IAV, com exceção da RU Mariano Procópio, apresentam melhores condições ambientais por constituem bairros essencialmente residenciais, com menor densidade de construções e circulação de veículos se comparadas às demais. A RU Mariano Procópio, apresentou o maior índice, com $39,8 \mathrm{~m}^{2}$, bem superior aos $15 \mathrm{~m}^{2} /$ habitantes. 
Análise do índice de áreas verdes...

Tabela 1: Índice de Áreas Verdes encontrado por Região Urbana

\begin{tabular}{|l|c|}
\hline \multicolumn{1}{|c|}{ Região Urbana } & IAV ( $\left.\mathrm{m}^{2} / \mathrm{hab}\right)$ \\
\hline Mariano Procópio & 39,8 \\
\hline Bom Pastor & 2,5 \\
\hline Poço Rico & 1,6 \\
\hline Jardim Glória & 1,6 \\
\hline Bairu & 1,5 \\
\hline Centro & 1,4 \\
\hline Jardim Santa Helena & 1,0 \\
\hline Santa Catarina & 0,9 \\
\hline Jardim Paineiras & 0,4 \\
\hline São Mateus & 0,3 \\
\hline Eldorado & 0,3 \\
\hline Santa Terezinha & 0,1 \\
\hline Santa Cecília & $($ Zero $)$ \\
\hline Mundo Novo & 0 \\
\hline Alto dos Passos & 0 \\
\hline Boa Vista & 0 \\
\hline Vale do Ipê & 0 \\
\hline Morro da Glória & 0 \\
\hline Fábrica & 0 \\
\hline Vila Ozanan & 0 \\
\hline Granbery & 0 \\
\hline Botanágua & 0 \\
\hline Manoel Honório & 0 \\
\hline Centenário & \\
\hline
\end{tabular}

Esse valor pode ser explicado pela presença do Parque e Museu Mariano Procópio, que apresenta uma área de 9ha, tombado pelo Decreto Municipal № 2861/83.

O Museu Mariano Procópio (Figura 3), como é conhecido pela população local, é a área verde mais expressiva apresentada na unidade estudado. Possui um agrupamento de espécies vegetais antigas, se comparada à arborização urbana da cidade, e constitui um parque que funciona associado ao museu histórico. É uma área que desempenha muito bem as funções de lazer, paisagísticas, sociais e, principalmente, ecológicas, no que diz respeito à permeabilidade do solo e à minimização da temperatura, graças à presença acentuada da arborização, constituindo-se numa ilha de frescor dentro do mosaico urbano. 


\section{FONTE: IPLLAN (1996).}

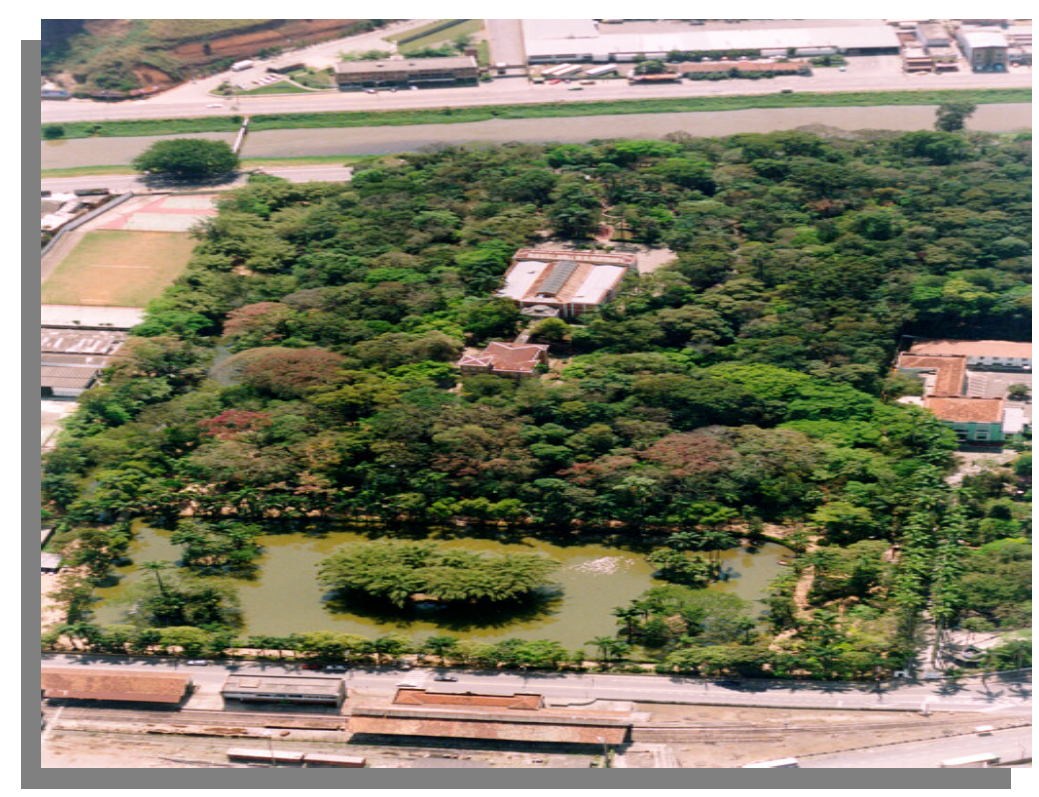

Figura 3: Vista aérea do Parque e Museu Mariano Procópio, Juiz de Fora/MG, apresenta alta densidade de arborização, e um lago (parte inferior da figura), que faz do museu a área verde mais significativa da área central de Juiz de Fora/MG.

A Região Urbana Centro, apesar do baixo IAV (1,4m²/hab), é sede de um parque de pequeno porte, conhecido como Parque Halfeld (Figura 4), localizado na principal avenida da cidade (Av. Rio Branco), uma das vias que comporta maior trânsito de veículos na cidade. Mas, assim como o Museu Mariano Procópio, o Parque Halfeld merece destaque em função de sua composição vegetal e funções sociais, estéticas e de lazer oferecidas por esta área em meio à grande densidade de construções. 
Análise do índice de áreas verdes...

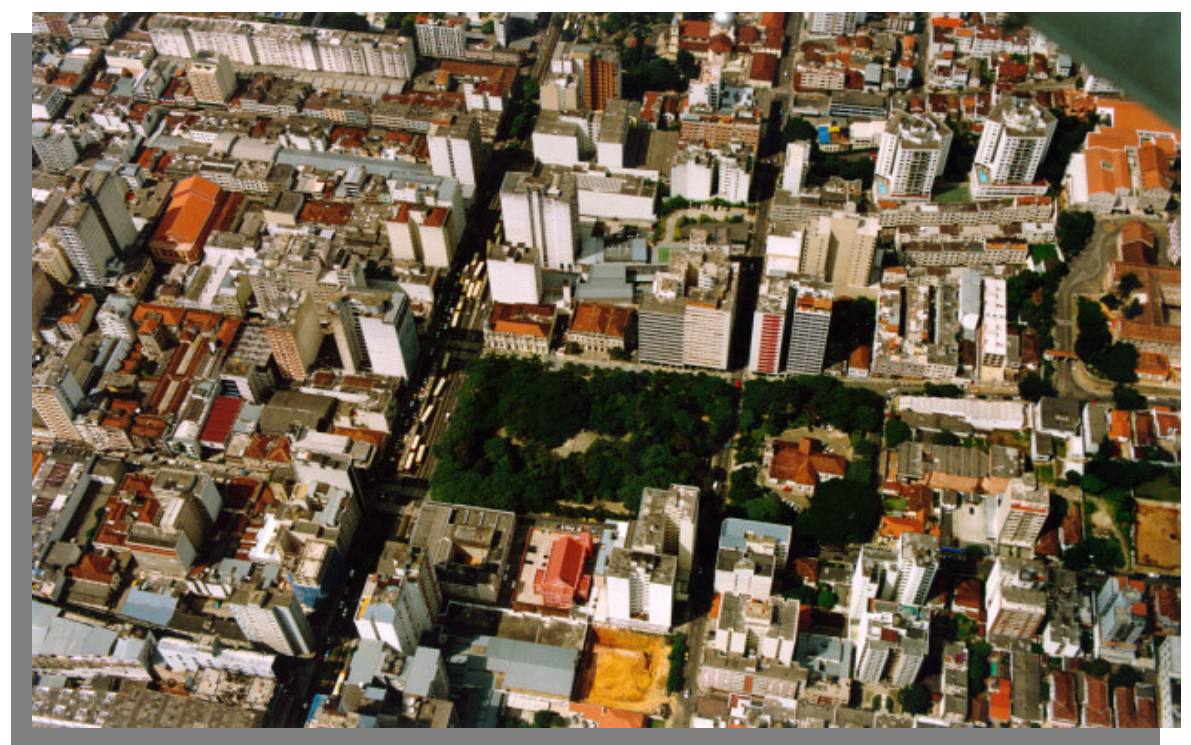

Fonte: IPLLAN (1996).

Figura 4: Vista aérea do Parque Halfeld, no centro da cidade de Juiz de Fora/MG, ao centro da figura é uma área bem arborizada, englobada pelo entorno densamente urbanizado, que sofreu nas últimas décadas um acelerado processo de verticalização.

Este parque, criado em 1854, tem significado histórico, paisagístico, urbanístico e ecológico para cidade. E teve importância cívica com relação à elevação de Juiz de Fora à categoria de Vila. Já no século XIX, em 1880, este local foi transformado em jardim público e em passou a ser denominado Parque Halfeld; tombado pelo Decreto $N^{\circ} 4223$ de 10 de novembro de 1989.

Áreas verdes como o Parque Halfeld e o Parque do Museu Mariano Procópio, desempenham um papel muito importante na área urbana, pela riqueza das combinações dos seus atributos na qualidade ambiental, contribuindo para regular as condições ecológicas, como redução do escoamento superficial, redução de materiais tóxicos particulados e gasosos e sua incorporação nos ciclos biogeoquímicos, minimização da amplitude térmica, etc.; funções estas defendidas por diversos autores (NUCCl, 1996; MASCARÓ, 2005; HENKE-OLIVEIRA, 1996), além de contribuírem, também, para qualidade de vida, fornecendo um ambiente ao ar livre que oferece um micro-clima mais agradável que fora destas áreas e condições de lazer e descanso diferenciadas do entorno urbanizado.

As RU's Santa Cecília, Mundo Novo, Eldorado e Vila Ozanan, e as RU's Boa Vista, e Vale do Ipê, apresentaram IAV igual a zero, com exceção da RU Eldorado, que apresentou $0,3 \mathrm{~m}^{2} /$ habitantes.

Em termos de oferta de áreas verdes à população situada nessas RU's, é possível constatar que, nenhuma dessas RU's oferecem condições à prática do lazer ao ar livre, ao contato com a vegetação ou aos benefícios oferecidos pela função ecológica 
desempenhada pela presença dessas áreas. Este fato leva, muitas vezes, crianças e adolescentes a buscar outros locais para o lazer, tal como, a utilização da via pública para prática de esportes. Ficando expostas aos perigos de atropelamento, por exemplo, já que, dividem a ruas com os veículos que aí circulam.

Todavia, as RU's Boa Vista, e Vale do Ipê representam um diferencial neste quadro. Mesmo apresentando um IAV zero, possuem uma população de nível sócio-econômico alto e excelentes padrões residenciais com jardins particulares, podendo, portanto, desfrutar ao menos dos benefícios ecológicos oferecidos pela presença da vegetação. Enquanto as demais RU's apresentam padrão de ocupação bastante inferior, com áreas construídas bastante adensadas sem a presença de quintais com vegetação.

Mesmo difundida a importância das áreas verdes, não só em termos ecológicos, mas também sociais, constituindo-se em um complemento necessário ao lazer, especialmente para as classes que não dispõem de recursos para buscar entretenimento fora da circunscrição urbana (MENDONÇA e MONTEIRO, 2003), este reduzido IAV verificado, representa uma clara contradição entre o discurso da necessidade das áreas verdes em prol da qualidade de vida, e o que pode ser verificado em realidade na unidade estudada.

Existem na cidade instrumentos normativos que prevê a criação de áreas livres, tais como a lei que dispõe sobre parcelamento do solo no Município de Juiz de Fora (Lei № 6908/86). Essa lei em seu Art. 10 define que, 35\% da área total do projeto de loteamento sejam destinadas a uso público, sendo 15\%, no mínimo dessas áreas, destinadas exclusivamente a equipamentos comunitários e áreas livres de uso público. Essa área formada ou mantida pelo projeto de loteamento deve ser constituída predominantemente por vegetação da flora nativa, sendo denominada área verde especial (Lei № 9896/00).

Entende-se que cálculo do IAV é de grande relevância como um indicador da presença ou ausência das áreas verdes. Todavia, trata-se de um índice, que indica se aquela região que se procurou analisar está dentro do recomendado ou não. Quando este índice indica presença dessas áreas, a preocupação, então, deve recair nas condições em que essas áreas se encontram, se são utilizadas para o fim a que foram destinadas, se sua localização é adequada e, ou, se atendem às necessidades da comunidade onde está inserida.

\section{CONCLUSÃO}

Os IAV's encontrados na área estudada estão muito abaixo do mínimo de $15 \mathrm{~m}^{2} /$ habitantes para assegurar a qualidade de vida da população situada nesta localidade, confirmando a baixa oferta de áreas verdes. Excetuando-se apenas a Região Urbana 
Análise do índice de áreas verdes...

Mariano Procópio, que apresentou o maior IAV com $39,8 \mathrm{~m}^{2}$, devido à presença do Parque e Museu Mariano Procópio, uma área verde de grande relevância para população.

Verifica-se que, apesar do entendimento dos benefícios oferecidos pelas áreas verdes, estarem, cada vez mais, difundidos na sociedade, a realidade que se apresenta, ainda, esta distante de ser o ideal almejado para promover a qualidade ambiental e de vida da população. Apenas o cumprimento da legislação vigente na cidade, já seria suficiente para garantir a criação e manutenção das áreas verdes.

Visto que área estudada integra a maior parte das regiões urbanas situadas na zona efetivamente urbanizada da cidade, e frente ao déficit de áreas verdes apresentado, tornase primordial a criação de um plano diretor de arborização e áreas verdes para a cidade, com objetivo manter e multiplicar essas áreas.

\section{REFERÊNCIAS BIBLIOGRÁFICAS}

ANUÁRIO ESTATÍSTICO. CPC - Centro de Pesquisas Sociais, Universidade Federal de Juiz de Fora. CD-ROM:. Anuário Estatístico 2005. Juiz de Fora - 2005.

BUCCHERI - FILHO, A. T. Qualidade Ambiental no Bairro Alto da XV, Curitiba/PR. Dissertação (Mestrado). UFPR. Curitiba, PR, 2006.

BUCCHERI - FILHO, A. T; NUCCI. J. C. Espaços Livres, Áreas Verdes e Cobertura Vegetal no Bairro Alto da XV, Curitiba/PR. Revista do Departamento de Geografia, UFPR, 18, 2006. p. 48-59.

CAVALHEIRO, F.; DEL PICCHIA, P. C. D. Áreas Verdes: Conceitos, Objetivos e Diretrizes para o Planejamento. In: I Congresso Brasileiro sobre Arborização Urbana e IV Encontro Nacional sobre Arborização Urbana, 1992. Vitória. Anais... Vitória, ES, 1992. p. 29-38.

CAVAlHeIRO, F. et al. Proposição de Terminologia para o Verde Urbano. Boletim Informativo da Sociedade Brasileira de Arborização Urbana. SBAU: AnoVII, n³ - jul/ago/set de 1999. Rio de Janeiro, RJ, 1999.

COSTA, R. G. S.; FERREIRA, C. C. M. Avaliação do Índice de Áreas Verdes (IAV) em 26 Regiões Urbanas na Região Central da cidade de Juiz de Fora, Minas Gerais. In: XII Simpósio de Geografia Física Aplicada, 2007. Anais... Natal, RN, 2007.

COSTA, R. G. S.; FERREIRA, C. C. M. Áreas Verdes, Espaços Livres e Verde Viário. In: III Encontro de Geografia da UFJF. Juiz de Fora, MG, 2008.

GUZZO, P.; CAVALHEIRO, F. Índices de Espaços Livres de Uso Público e de Cobertura Vegetal em dois Setores Urbanos da Cidade de Ribeirão Preto/SP. In: V Congresso Brasileiro de Arborização Urbana, 2000. Rio de Janeiro. Anais... Rio de Janeiro, RJ, 2000. 
HARDER, I. C. F. Inventário Quali-Quantitativo da Arborização e Infra-Estrutura das

Praças da cidade de Vinhedo (SP). Dissertação (Mestrado). Escola Superior de Agricultura Luiz de Queiroz. Piracicaba, SP, 2002.

HENKE - OLIVEIRA, C. Planejamento ambiental na Cidade de São Carlos (SP) com ênfase nas áreas públicas e áreas verdes: diagnósticos e propostas. Dissertação (Mestrado). UFSCar. São Carlos, SP, 1996.

HENKE - OLIVEIRA, C. et al. Caracterização preliminar das Áreas Verdes Públicas de São Carlos - SP. In: II Congresso Brasileiro sobre Arborização Urbana. 1994. São Luiz: Anais... Sociedade Brasileira de Arborização Urbana, 1994. p. 295-307.

IBGE. Contagem Populacional. Censo, 2000. Disponível em <http:www.ibge.gov.br> Acesso em 03/04/2005.

IBGE. Estimativa Populacional para 2007. Disponível em <http:www.ibge.gov.br> Acesso em 24/10/ 2007.

IPPLAN/JF. Plano Diretor de Desenvolvimento Urbano de Juiz de Fora. Juiz de Fora: IPPLAN, 1996.

LAPOIX, F. Cidades Verdes e Abertas. In: Enciclopédia de Ecologia. São Paulo-SP: USP, 1979.

LIMA, A. M. L. P. et al. Problemas de Utilização na Conceituação de termos como Espaços Livres, Áreas Verdes e Correlatos. In: II Congresso Brasileiro sobre Arborização Urbana, 1994. São Luis: Anais... São Luis: Sociedade Brasileira de Arborização Urbana, 1994. p. 539-553.

MARTINS, L. A. A Temperatura do ar em Juiz de Fora-MG: Influências do sítio e da estrutura urbana. Dissertação (Mestrado). UESP. Rio Claro, SP, 1996.

MARTINS, L. A., TORRES, F. T. P. A Influência de Fatores Antrópicos e meteorológicos na Qualidade do Ar de Juiz de Fora - MG. Juiz de Fora-MG. Disponível em <http://www.labcaa.ufjf.br>. Acesso em 14/11/2005, 2001.

MASCARÓ, L; MASCARÓ J. Vegetação Urbana. 2ed. Porto Alegre: Editora +4, 2005.

MAZETTO, F. A. P. Qualidade de Vida, Qualidade ambiental e meio Ambiente Urbano:

Breve Comparação de Conceitos. Revista Sociedade e Natureza, Uberlândia -MG. 12(24):21-31, jul/dez. 2000.

MENDONÇA, F.; MONTEIRO, C. A. F. Clima Urbano. Ed: Contexto. 2003.

MILANO, M. S. Planejamento da Arborização Urbana: relações entre Áreas Verdes e Ruas Arborizadas. In: IV Encontro Brasileiro sobre Arborização Urbana, 1990. Curitiba. Anais... Curitiba: Sociedade Brasileira de Arborização Urbana, 1990.

MOURA, A. R.; NUCCI, J. C. Análise da Cobertura Vegetal do Bairro de Santa Felicidade, Curitiba/PR. Anais... XI Simpósio de Geografia Física Aplicada. USP, São Paulo, 2005. 
Análise do índice de áreas verdes...

NUCCI, T. C. Qualidade Ambiental e Adensamento Urbano: um estudo de ecologia e planejamento da paisagem aplicada ao distrito de Santa Cecília (MSP). São Paulo-SP: Humanitas. FFLCH. USP, 2001.

$\mathrm{NUCCl}$, João Carlos. Qualidade Ambiental e Adensamento: um estudo de planejamento da paisagem do distrito de Santa Cecília (MSP). Tese (Doutorado). São Paulo-SP. USP, 1996.

PAIVA, H. N.; GONÇALVES, W. Florestas Urbanas: planejamento para melhoria da qualidade de vida. Viçosa, MG: Aprenda Fácil (série arborização urbana; v.2), 2002.

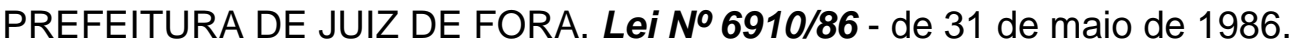

PREFEITURA DE JUIZ DE FORA. Lei No 6908/86 - de 31 de maio de 1986.

PREFEITURA DE JUIZ DE FORA. Lei No $^{\mathbf{7} 619 / 89}$ - de 13 de outubro de 1989.

PREFEITURA DE JUIZ DE FORA. Lei No 9896/00 - de 16 de novembro de 2000.

PREFEITURA DE JUIZ DE FORA. Decreto $\mathbf{N}^{\circ} \mathbf{4 1 2 8 / 8 9}$ - de 30 de março de 1989

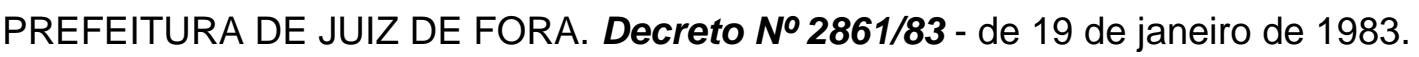

PREFEITURA DE JUIZ DE FORA. Decreto $\boldsymbol{N}^{\circ} \mathbf{4 2 2 3 / 8 9}$ - de 10 de novembro de 1989.

REZENDE, R. F. et al. A relação entre a Incidência das Áreas Verdes e as Taxas de

poluição do Ar na Porção nordeste da cidade de juiz de Fora-MG. In: XI Simpósio Brasileiro de Geografia Aplicada, 2005, São Paulo. Anais... São Paulo: Departamento da Geografia, 2005.

ROSSET, F. Procedimentos Metodológicos para estimativa do Índice de Áreas Verdes Públicas. Estudo de Caso: Erechim, RS. Dissertação (Mestrado). UFSCar. São Carlos, SP, 2005.

SANTOS, E. O.; SANTOS, T. O. MENDES, D.; MARTINS, L. A. Urbanização e Alterações Microclimáticas em Juiz de Fora-MG. Anais. . . XI Simpósio de Geografia Física Aplicada. USP, São Paulo-2005.

SBAU. Sociedade Brasileira de Arborização Urbana. Carta a Londrina e Ibiporã. Boletim Informativo. v.3, n.5, 1996. p. 3.

SILVA, A. B. Sistemas de Informações Geo-referênciadas: conceitos e fundamentos. Campinas, SP: Editora da Unicamp, 1999.

STAICO, J. A Bacia do Rio Paraibuna em Juiz de Fora: a natureza. Ed. UFJF. JF, 1976. 